\title{
Traditional knowledge on wild and cultivated plants in the Kilombero Valley (Morogoro Region, Tanzania)
}

\author{
Mirko Salinitro ${ }^{1,2}$, Renzo Vicentini ${ }^{2}$, Costantino Bonomi ${ }^{2}$ and Annalisa Tassoni ${ }^{1 *}$
}

\begin{abstract}
Background: This research was performed in four villages adjacent the boundary of Udzungwa Mountains National Park in the Kilombero River plain of Tanzania. The area adjacent the villages is characterized by self-consumption agriculture, with a population that is on average poor, still very tied to traditions and almost entirely unaffected by modernization and technology. The aim of the present study was to investigate and record local knowledge regarding the use of wild and traditionally cultivated plants used for traditional medicine and for other everyday purposes (e.g., food, fibers and timber).

Methods: Ten traditional local healers, with solid botanical knowledge, were interviewed between June and August 2014 by means of semi-structured questionnaires. For each mentioned plant species, the Swahili folk name and, when possible, the classification by family, genus and species was recorded as well as the part of the plant used, the preparation method and the main uses (medicine, food or others).

Results: In total 196 species were mentioned of which 118 could be botanically classified. The identified species belong to 44 different botanical families, with that of the Leguminosae being the most representative (24 species).

The plants were mostly used as medical treatments (33.3\% of the species) and foods (36.8\%), and to produce wood and fibers (19.4\%).

Conclusion: The present study revealed that numerous plant species are still essential in the everyday life of the tribes living in Kilombero Valley. Most of the plants were usually harvested in the wild, however, after the creation of the Udzungwa Mountains National Park, the harvesting pressure has become concentrated on a few unprotected forest patches. Consequently, many useful species are becoming increasingly rare with the risk of losing the connected botanical and traditional knowledge. The present study may, therefore, contribute to record the ethnobotanical knowledge held by these populations, in order to preserve this valuable richness for future generations.
\end{abstract}

Keywords: Ethnobotany, Ethnomedicine, Medicinal plants, Udzungwa Mountains National Park, Kilombero Valley

\section{Background}

Synthetic materials replaced nowadays many traditional plant-derived products having an increasing impact on the ethnobotanical culture of traditional societies. However, both wild and cultivated plants still remain vital to many aspects of traditional life [1]. In particular, plant species provide humans many type of building materials such as timber, poles and fibers [1-3]. Timber, the major

\footnotetext{
*Correspondence: annalisa.tassoni2@unibo.it

'Department of Biological, Geological and Environmental Sciences, University of Bologna, via Irnerio 42, 40126 Bologna, Italy

Full list of author information is available at the end of the article
}

forest product, has a considerable importance in the construction of temporary shelters, permanent homesteads and fences within the traditional societies [1], stems and leaves of grasses and palms are used in roof covering [2]. Plant parts have also additional uses in traditional arts and handicrafts including tool handles, cooking utensils, baskets, cordage and textiles [1, 4]. Likewise, plant extracts are sources of dyes, gums, latex, waxes, resins and adhesives $[1,2]$. The most important uses of plants in developing countries (such as Tanzania) are however for fuel and medicine $[5,6]$. 
In Tanzania, about $69 \%$ of the population lives in rural areas [7] where forest resources are central to their livelihood. Furthermore, according to the World Health Organisation (WHO), up to $80 \%$ of the population in developing countries depend on locally available plant resources for their primary healthcare [8]. In Tanzania, traditional medicine provides health care and support to over $60 \%$ of the rural population $[9,10]$. This trend is mainly due to the strong attachment to traditions and spirituality and to the greater access, with respect to conventional medicine, to healers inside villages that provide low cost treatments [11]. The traditional medical treatments are mainly based on herbal remedies, using sometimes many different species mixed together $[4,12]$. Except for a few plant species that grow inside or close to the villages, most of the used species are collected in forest areas [13].

Almost all the remaining forests in Tanzania are now found in protected areas, but in a few locations, with lower human population density, some unprotected forest patches [14] still remain. Public forest lands are freely available for use, whereas the exploitation of natural reserves is restricted by the issuing of licenses. Most of the unprotected forest land comprises miombo woodland (by the Swahili name of the common genus Brachystegia) which provides food, fuel, construction materials and medicines but is seriously threatened by overexploitation [15].

In Kilombero Valley (Morogoro region, where the present study was located, Fig. 1) deforestation was caused by the need to obtain land for agriculture and for the establishment of teak (Tectona grandis L.f.) and eucalyptus (Eucalyptus globulus Labill) plantations, as well as by charcoal production from cutted trees. Nonetheless the remaining lowland forest are still not protected unlike the neighbouring Udzungwa Mountains where a strong protection is carried out on the entire elevational range of the forest [14].

For years, local healers could bypass the restrictions for access to National Parks, but given the increasingly strict rules, they have lately been forced to change their places of collection with a serious impact on everyday life. In fact, the knowledge and experience of each traditional healer are deeply linked to the place where he/ she learned and practiced plant collection over the years. There are now few forest areas in Kilombero Valley that can provide therapeutic plants. These are located far from the villages, and some of the collection methods, such as decortication, could be extremely impactful when carried out in small areas, making the plants unusable after a few years.

Since the founding of Udzungwa Mountains National Park, more than 24 years ago, there has been a depletion of the traditional medical culture, due to the forced abbandonement of familiar areas of collection, as well as the progressively more difficult transmission of knowledge to and training of young healers. Finally, the cost of traditional medicine is now starting to grow, causing a significant problem for people who have always relied on this method for their healthcare [11]. Since the 1970s, international health policy began to take interest in traditional medicine in Tanzania [11]; with the Traditional and Alternative Healthcare Practice Act 2002, the government recognizes traditional medicine as being important in the healthcare of its people. However, despite legislation being in place, not much progress has been made in the documentation and evaluation of the vast resource of medicinal plants used by traditional healers [16] and no actions have been taken to solve problems related to plant gathering practices.

Previous ethnobotanical studies have been conducted in Tanzania with the main purpose to investigate

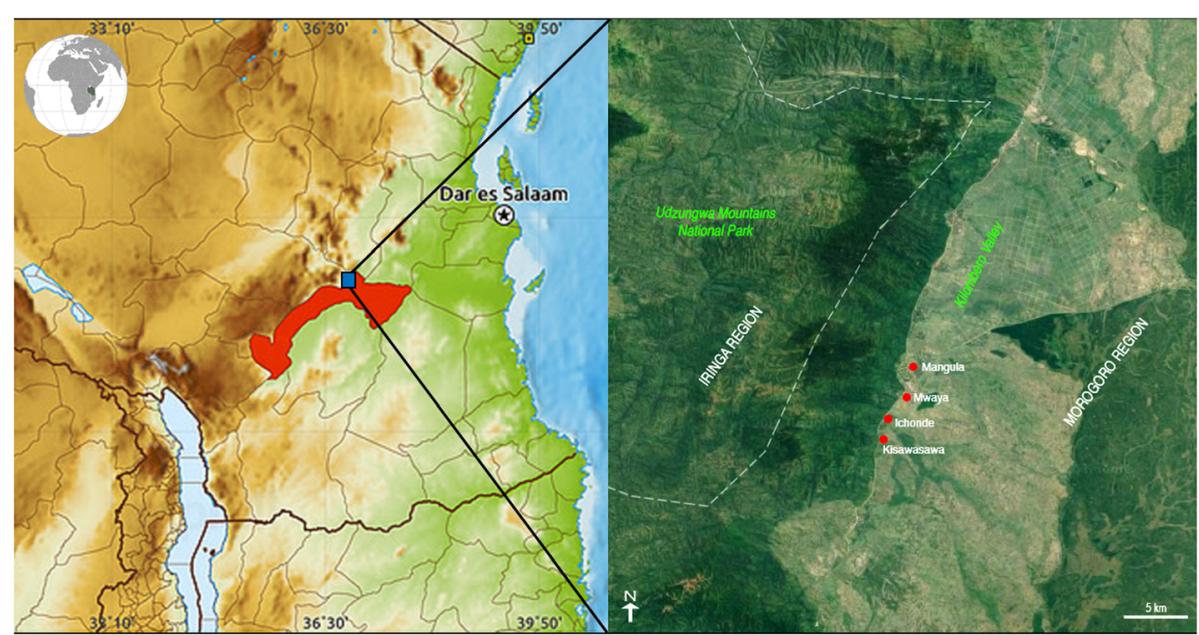

Fig. 1 Study area. The enlargement shows the location of the four villages where the interviews took place 
ethnomedicinal knowledge of local healers [9, 12, 13, 16-18], but only few have been carried out in the Morogoro region $[5,19,20]$. Some studies were also aimed at obtaining general ethnobotanical knowledge, including plant uses other than medicinal ones [5, 21].

The present study was carried out in four villages located between the agricultural area of Kilombero Valley and Udzungwa Mountains National Park (Morogoro region) (Fig. 1), in which the people obtain most of the raw materials for every day life and most medicinal plants from the forest environment [19]. Until 1992, year of the establishment of the Udzungwa Mountains National Park [22], the inhabitants of the area had free access to the forest and were able to dispose of its resources in an easy and sometimes indiscriminate way. Successively, restrictions have been introduced to limit the collection of plants inside the park, until the complete ban since 2011. Despite the efforts, made by the Authority managing the park and by nonprofit organizations to educate the inhabitants of neighbouring villages to become independent from the forest, the total prohibition of using the park had a profound effect on people's lifestyle and most of the traditional medicine practices.

The aim of the present research was to collect data about plants, both cultivated and wild, used for traditional medicine and for other everyday purposes (e.g., food, fibers, timber), in order to preserve an important endangered part of the local cultural heritage. In fact, if in general ethnobotanical knowledge is being progressively lost all over Africa due to modernization and globalization, this is even more so in the Udzungwa Mountains, where all the activities closely related to the use of plant natural resources are limited by the strict rules and regulations of the National Park.

\section{Methods}

\section{Study area}

The study was carried out in four villages (Mangula, Muaya, Ichonde, Kisawasawa), located close to the southern limit of the Udzungwa Mountains National Park (Morogoro region, Tanzania), in the large agricultural plain of the Kilombero river (Fig. 1). The study area, is dominated by a dry climate, with $750 \mathrm{~mm}$ of average annual rainfall. The climate is defined biseasonal and the annual variations are determined by the monsoons coming from the Indian Ocean. The hottest period starts in December and lasts until March. During this period, rainfall is abundant and the average maximum temperature is in December around $26.9^{\circ} \mathrm{C}$. The rain season reaches its peak in April. The dry and fresh season begins in May and lasts until October. The cooler months are June and July with an average temperature of $21.5{ }^{\circ} \mathrm{C}$ (https://it.climate-data.org/location/3040/). The vegetation of the area is mainly represented by Miombo woodlands, a subtropical formation typical of semi-arid and arid climate. Miombo is the Swahili word for the Brachystegia genus, which is the dominant tree in this natural environment together with Julbernardia and Isoberlinia, of the subfamily Caesalpinioideae. Artificial grassland and shrublands are also present due to human activities [23].

The lack of industrialization, the remoteness from urban centers, the proximity to mountains and the generalised poverty make this location a perfect nursery for the growth and preservation of ethnobotanical knowledge. In fact, in this area the effects of globalization are still very weak and the people are usually closely tied to their traditions.

In these communities, agriculture is the main economic activity, together with some animal husbandry often finalized to self-consumption, and the cultivated species are not numerous $[5,6]$. Beside rice and corn, many other vegetables are grown, mostly belonging to the Solanaceae, Brassicaceae, Amaranthaceae and Cucurbitaceae families. Fruit trees, such as Prunus persica (L.) Batsch, Persea americana Mill., Mangifera indica L. and Annona sp., are also present on farms and in gardens [5]. The people of these villages depend on the Miombo forest not only for food, but also for the supply of wood and coal, that remain the most widely used fuels for cooking, brick making and woodworking. Other products that derive from the forest are the majority of natural fibers, for the production of ropes, baskets and rugs, and most of the medicinal plants [19].

\section{Selection of the informants and interview method}

In general, ethnobotanical studies performed for cognitive and preservative purposes of local knowledge aim at collecting as much information as possible [24]. However, when conducting interviews, it is sometimes useful to select a preferencial topic to avoid wasting time, but above all, to investigate and preserve a specific and sometimes mostly endangered type of knowledge.

In the present study, beside the collection of general ethobotanical information, the attention was focused on plant medicinal use. The selection of candidates for interviews was performed with the collaboration of the Mazingira Association (http://www.mazingira.net/) that runs environmental education projects in the study area and operates in close contact with the resident population. Given the limited extension of the study area and the hesitancy of some local healers in sharing their knowledge, it was possible to interview only ten people.

The interviewes were carried out between June and August 2014, to ten candidates belonging to seven different tribal groups (Hehe, Pare, Chaga, Pogoro, Luguru, Mndamba, Mndegereko) with four people belonging to the Hehe group, predominant in this territory [12].

Each informant was interviewed individually for one or more times, according to his amount of knowledge. 
The interviews were always held in familiar places, to make it easier for the interwiewee to find the species with whom he/she is familiar. Each interview was conducted in Swahili language and mediated by an interpreter (Swahili-English) to allow the respondent to easily express his/her knowledge. For completeness and standardization of collected information, interviews were conducted by means of semi-structured questionnaires [25] (Additional file 1). The questionnaires were specifically developed for the purposes of the present study, based on a previous ethnobotanical research [26].

The interview consisted of three steps. At the first meeting, interviewer and informant were introduced to each other, the objectives of the study were explained in detail and the informed consent of the candidate to the interview, filming and taking photographs was acquired (Additional file 1). In a second phase, the personal information of the respondent, such as age, tribal group, profession and education level, was collected through a semi-structured questionnaire. Finally, the ethnobotanical knowledge was investigated. For each mentioned plant species, the informant was asked to provide information regarding the parts of the plant used, the method and period of harvesting, possible uses (e.g., food, fiber production, timber, spiritual uses, etc.) and whether the plant is still commonly used. Although a pre-structured questionnaire was used for the collection of this information, the candidate was left to speak freely and only at the end of the discussion specific questions were addressed to complete the data. Each interview was itinerant and took place under the guidance of the candidate, who was moving within the territory from which he/she usually collects plants, to directly show the plant species. The interviews usually took place in the morning before lunch and lasted between 3 and $4 \mathrm{~h}$. After each interview, the candidate was payed 5000 Tsh (about 2.10 Euros) as compensation for the time spent. In addition, candidates received a paper, written in English and Swahili, with the purposes of the study to which they had just contributed. During the interviews, specimens were collected for an herbarium (Fig. 2a), after having acquired permission from the interviewee for plants located on his/her private property. Plant samples were never collected inside protected areas, therefore, when it was not possible to collect herbarium samples, detailed photographs of the plant species and of the used parts were taken.

All material was immediately tagged and marked by a progressive code of five numbers (Fig. $2 b$, Table 1): the first two digits indicate the respondent, while the following three digits identify the plant species. The plants (both in the form of herbarium samples and/or photographs) were firstly classified on the basis of diagnostic characters and validated by using the correspondence

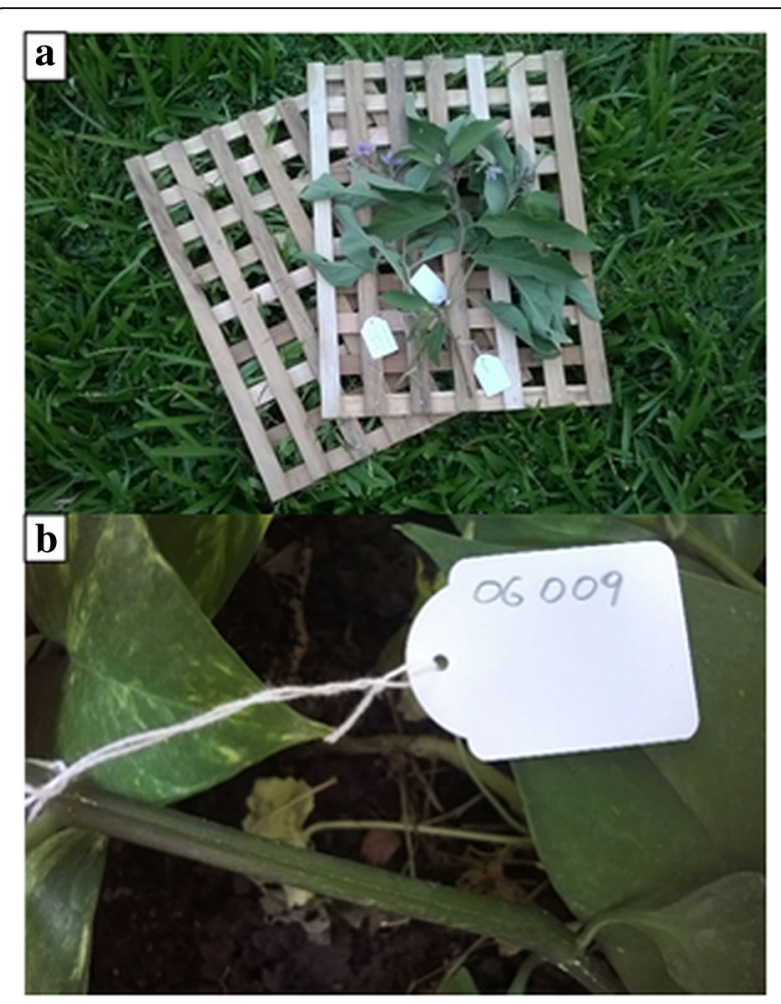

Fig. 2 Plant sample collection and numbering. a Solanum incana specimen ready to be dried and pressed; $\mathbf{b}$ example of collection number

with the folk name provided by the informant (Table 1). All the plant samples were delivered to the Department of Botany of Dar-es-Salaam University where voucher specimens were collected and deposited. The plant species were classified following the standard botanical nomenclature according to The Plant List (http:// www.theplantlist.org/).

Despite all efforts, 78 plant species could not be classified given the lack of samples and sometimes of diagnostic characters in the specimens. The unidentified plants are listed in the Additional file 2 using just the vernacular name given by the informant. Even tough the interviewees exactly described the medical proprieties and other uses of these plant species, they were not included in the following data processing.

\section{Results and discussion}

\section{Informants}

In total ten informants were interviewed, three women and seven men, aged between 31 and 86 years, with a mean age of 53 and a median of 53. Six respondents were over 50 years old. Ethnobotanical knowledge was not equally shared between the two genders and the average number of quoted species was 13.7 for men and 7.3 for women. On average, male informants reported 5.8 food plants and female 5.6. Similarly, the number of 


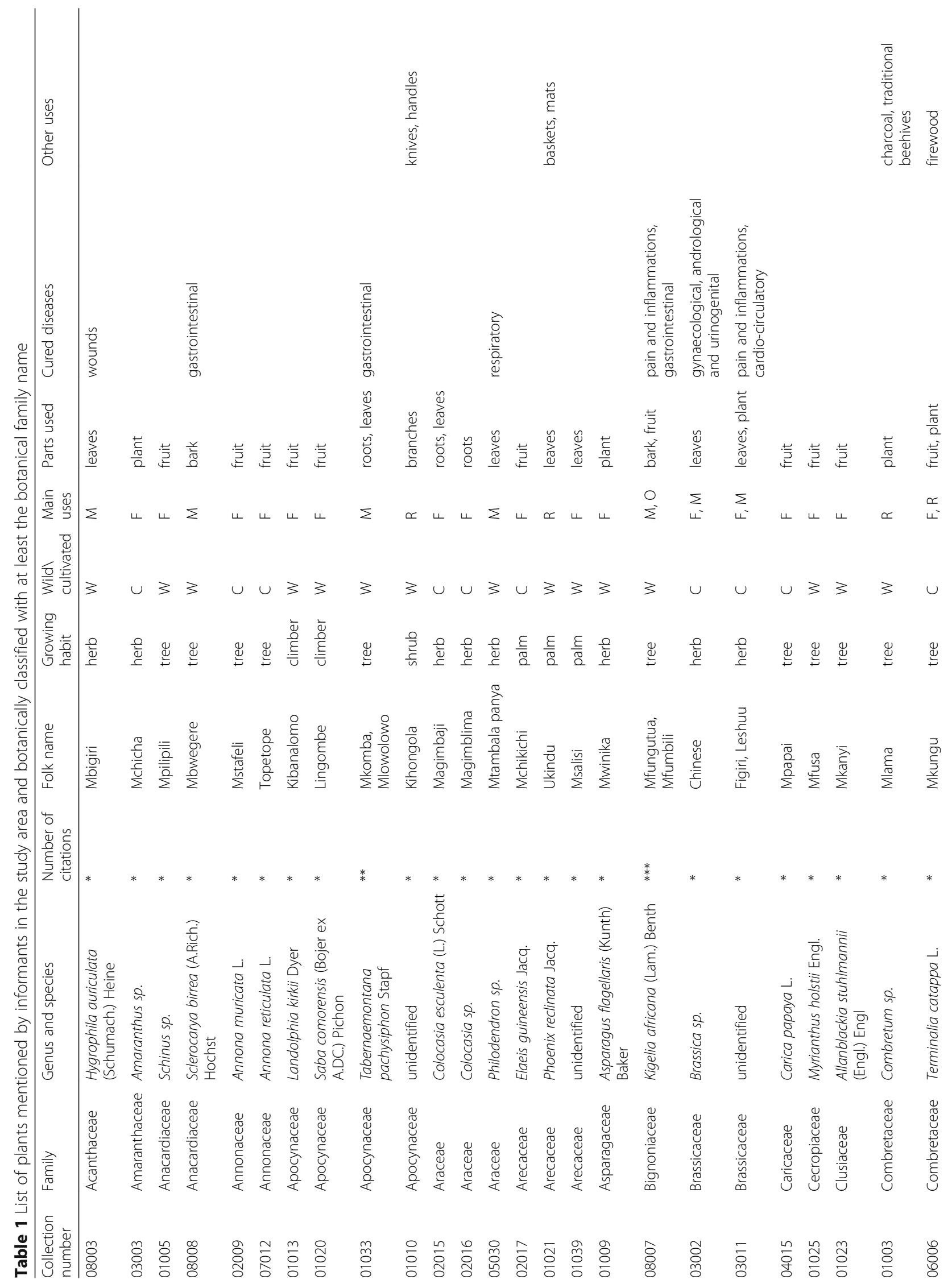




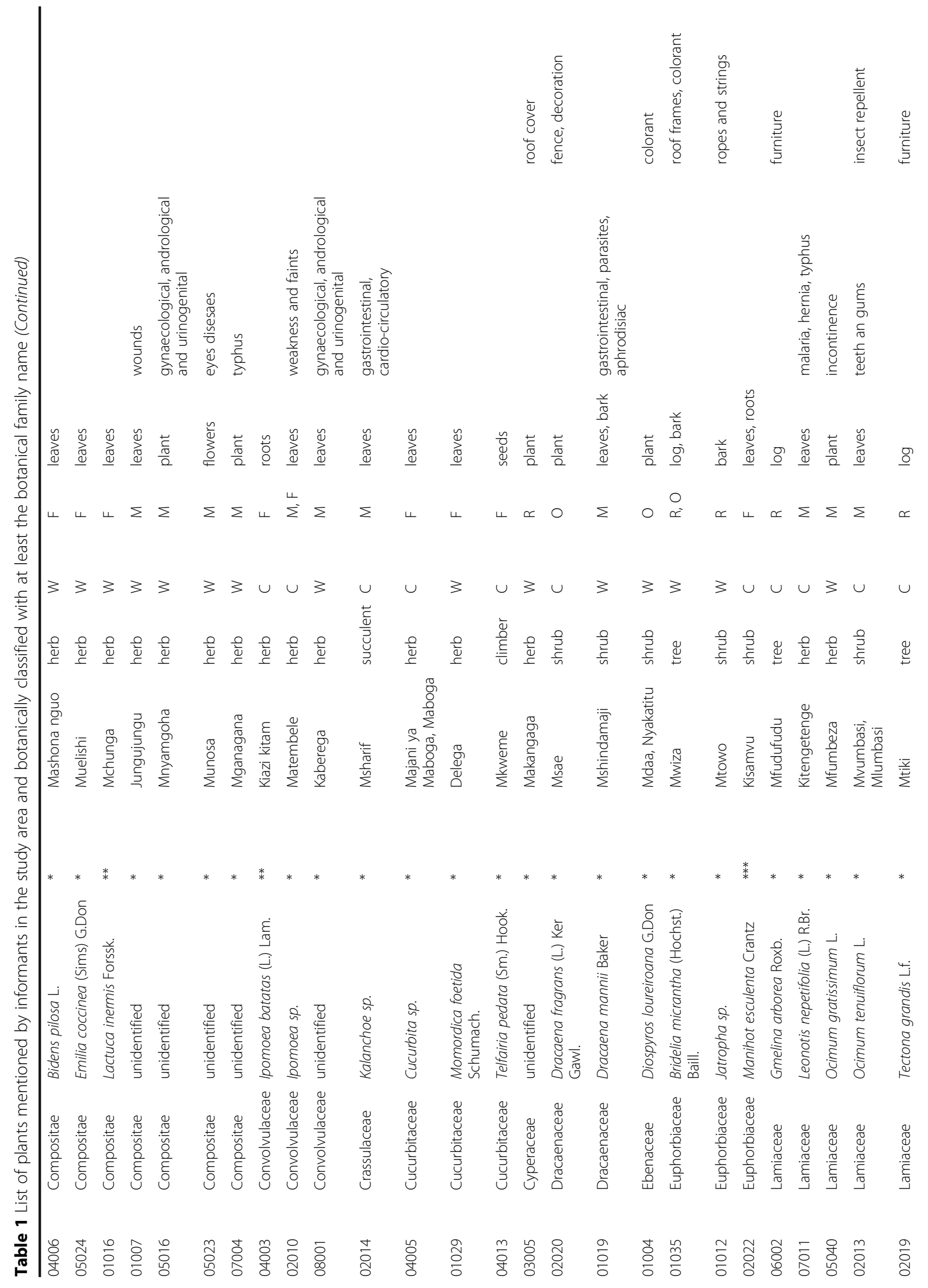




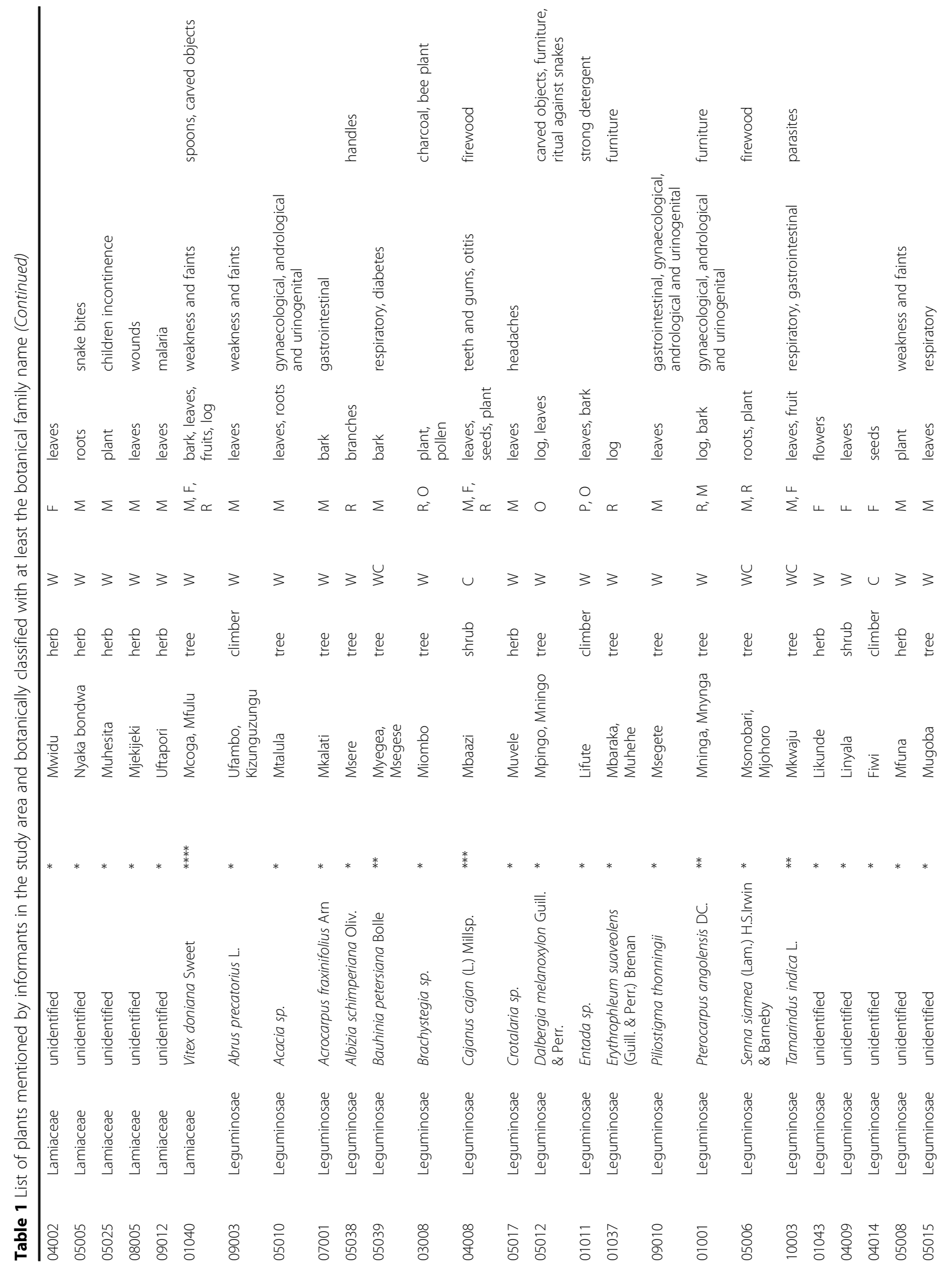




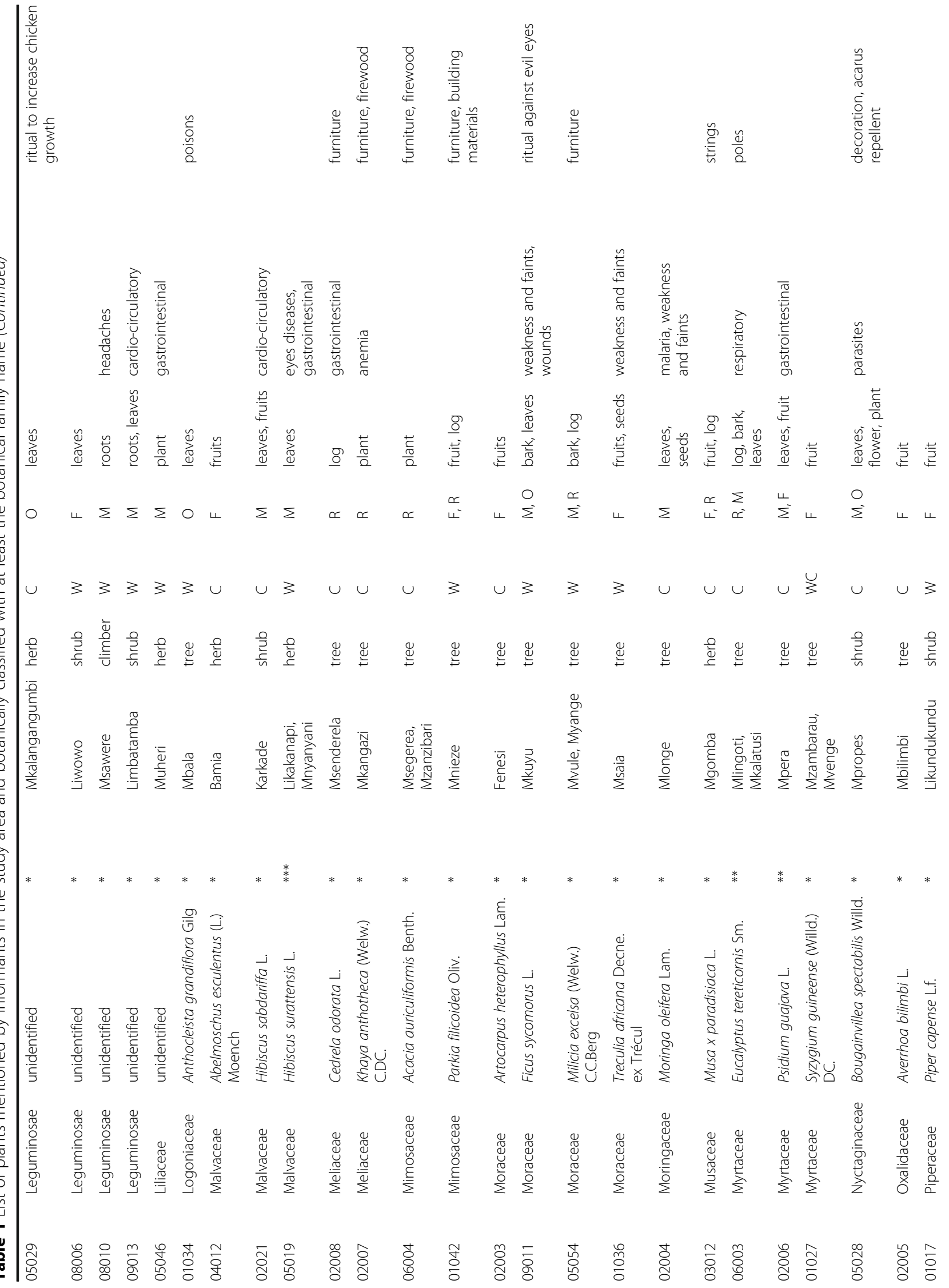




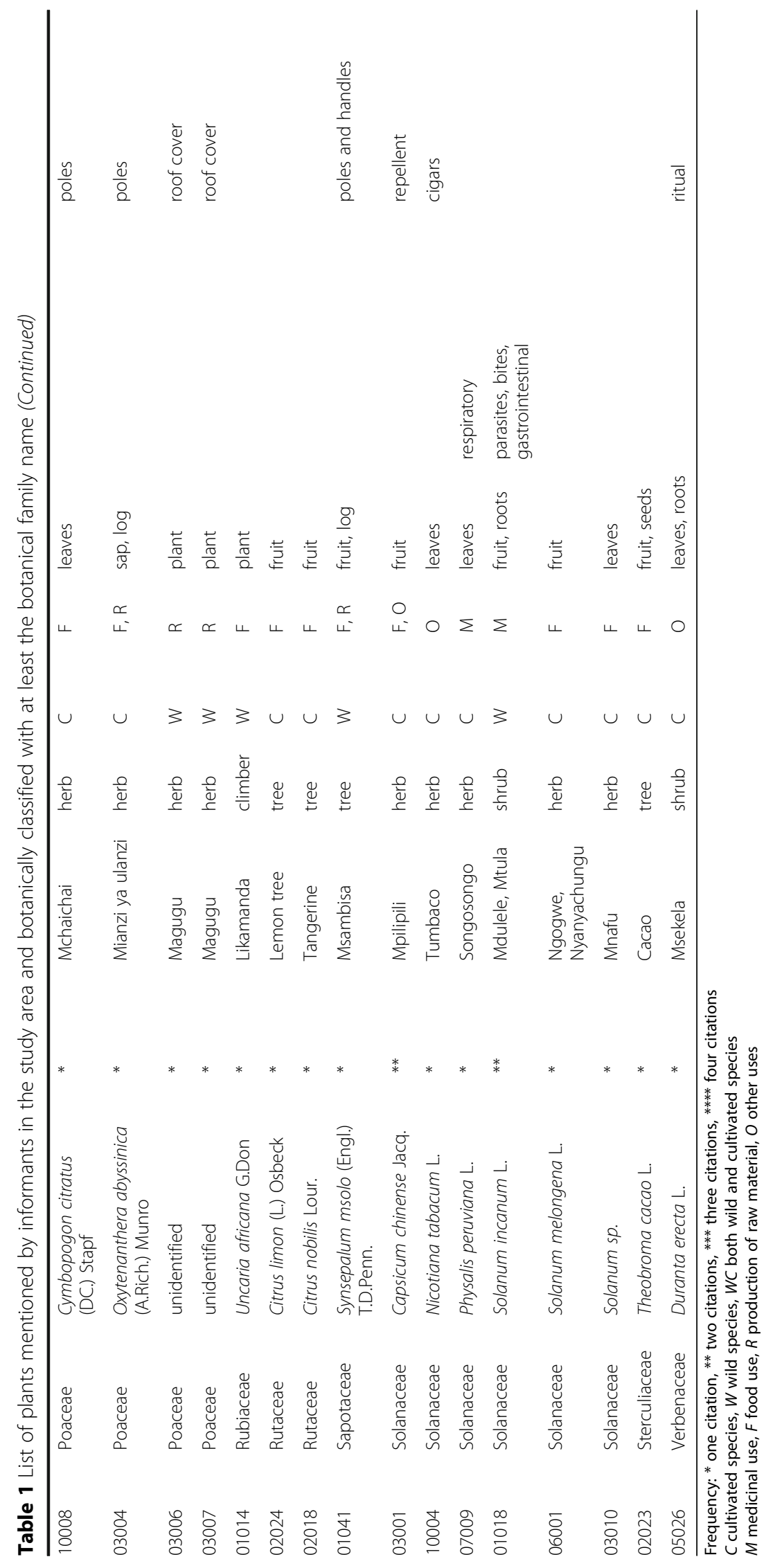


medicinal species cited was 5.7 for males and 6.0 for females. This reflects the fact that traditional ethnobotanical knowledge equally passed on through both the male and female line.

The informants were traditional healers as first or second job and all practiced farming. The respondents belonged to different ethnic groups: four were of the Hehe tribe, the dominant tribal group in the investigated area, while the other six candidates were one each of the Pare, Chaga, Pogoro, Luguru, Mndamba, Mndegereko tribes. On average education level was low, with nine candidates having attended just primary school and only one who also attended secondary school.

\section{Data on plant species}

Overall 196 different plant species traditionally used in the four villages of the study area were mentioned. For 118 samples, at least the family and, in most cases, the genus and species were idientified (Table 1), while for 78 plants only the folk name was available despite the efforts of classifying them (Additional file 2). Taking into consideration similar researches conducted in study areas neigbouring the Kilombero valley, the percentage of identified species (Table 1) in common with previous studies was $15.3 \%$ respect to those detected by Amri et al. [5], 20.3\% respect to Shangali et al. [19] and 5.9\% respect to Chrispin et al. [20].

Most of the plant species belonged to the family of Leguminosae (24), followed by Lamiaceae (11), Compositae (7) and Solanaceae (6) (Fig. 3). This result is in agreement with similar studies carried out in the Morogoro region [18] and other areas of Tanzania, where Leguminosae, Compositae and Solanaceae were among the most aboundant families $[13,16,18]$. In comparison

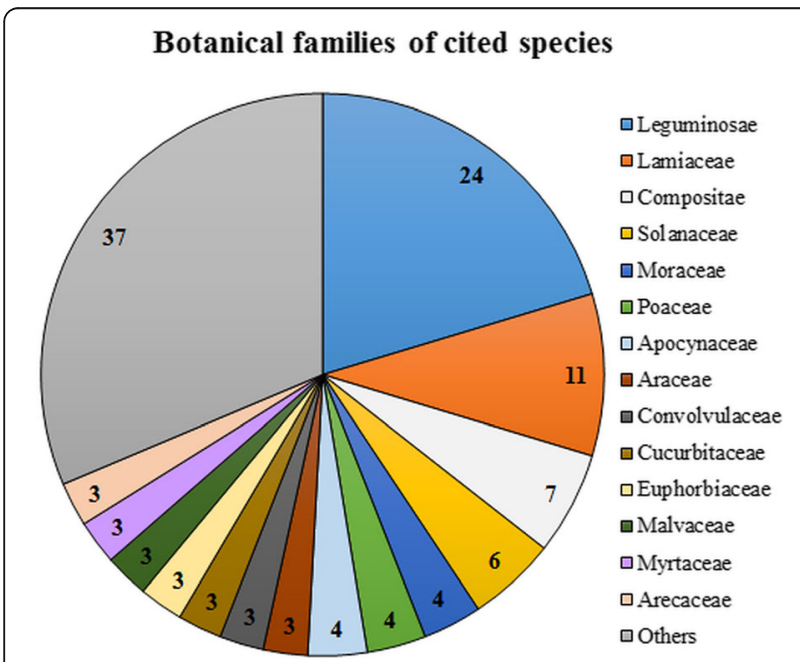

Fig. 3 Main botanical families of plant species mentioned by informants in the Kilombero Valley with previous studies $[13,16,18]$, the present data revealed a large presence of Lamiaceae, probably due to the widespread coltivation of this plant family (e.g., Ocimum tenuiflorum L., O. gratissimum L.) around the villages. Data evidenced the absence of plants belonging to the Rubiaceae family, as instead previously detected in other studies in the Morogoro region [18]; this was most probably due to the lack of forest areas nearby the studied villages and to the fact that most plants were collected in grassland and shrub areas, where this family is rarely present. Of all recorded species, $38.1 \%$ were trees, $38.1 \%$ herbs, $13.6 \%$ shrubs, $6.8 \%$ climbers, $2.5 \%$ palms and $0.8 \%$ succulent plants, which is again in accordance with previous studies which detected a large prevalence of tree species $[5,13]$. Of the 118 identified species (Table 1), 67 were collected in the wild, 47 were cultivated and 4 were both cultivated and spontaneous, such as Tamarindus indica L. Overall, 52\% of the reported useful species were exotic plants, while the remaining $48 \%$ were native plants.

Ethnobotanical knowledge is very diverse among the various tribes and for this reason multiple citations of plants by different healers are usually rare [12] (Table 1). The most cited plant is Vitex doniana Sweet (by 4 respondents), commonly used to prepare a tonic and energizing infusion. Manihot esculenta Crantz, Kigelia africana (Lam.) Benth., Cajanus cajan (L.) Millsp. and Hibiscus surattensis L. were cited by 3 respondents, but while the first is only used as food, the other three species are used for many purposes, including food, fuels, medicine and rituals (Table 1).

\section{Uses of cited species}

Most of the identified species were used for food purpose $(36.8 \%)$, and medicinal use (33.3\%), followed by production of raw materials, such as wood and fibers (19.4\%), and ritual use (3.5\%) (Fig. 4). When considering the totality of the mentioned species (196, Table 1 plus Additional file 2), the medicinal species represented the majority (45\%), which is in agreement with other studies carried out in the Morogoro region [5].

Of the identified plants (Table 1), 79.7\% have only one use, $18.6 \%$ have two uses (e.g., Psidium guajava L., used as food and medicine) and 1.6\% have three different uses (e.g., C. cajan L. Millsp, used as medicine, food and fuel). Some of the mentioned plants (14 species among which $V$. doniana, Synsepalum msolo (Engl.) T.D.Penn., Parkia filicoidea Oliv. and Milicia excelsa (Welw.) C.C.Berg) are highly valued trees, not only as food (for their edible fruits) and medicines, but also as firewood and timber. This fact is causing a fast depletion of the number of individuals of these wild species due to the indiscriminate cutting down of the trees. 


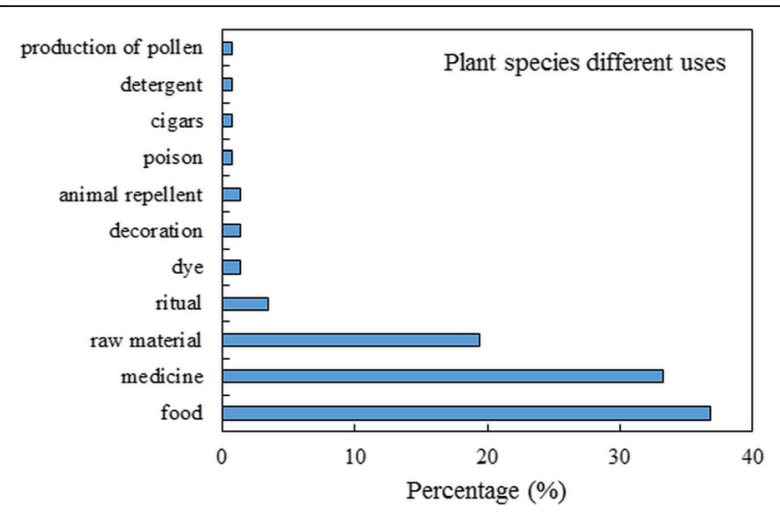

Fig. 4 Different uses of the plant species mentioned by informants and botanically classified in the study area

\section{Medicinal use}

The parts of the plants (Fig. 5a) mainly used for the preparation of herbal remedies were leaves $(50 \%)$, bark (16.7\%, Fig. 6a), roots (13.3\%), whole plant (10\%), fruits (6.7\%) and other parts like sap or flowers (3.3\%). A similar distribution was found by other studies in Africa $[5,13,16,18]$, with in general leaves representing the most frequently used plant part for medicine. Conversely, other studies reported roots as the most used part in preparing drugs $[12,27]$.
Most of the medicinal plants mentioned by the informants were usually harvested in the wild (32 species), while only few were cultivated (13 species). Therefore, plant harvesting methods have a deep impact on the natural ecosystem. In fact, while the collection of leaves somehow preserves the integrity of the plant, the excavation of roots and decortication, have extremely deleterious effects on plant individuals leading to their premature death. According to the opinion of the informants, many of the medicinal species subjected to such practices are at present seriously threatened and are becoming increasingly rare in their habitats. This triggers a vicious cycle of an even larger exploitation of the remaing specimens, which will accelerate their disappearance as already reported by Amri et al. [5] in other Morogoro region sites.

In $71.4 \%$ of cases, the mentioned medicinal plants were indicated for the treatment of a single disease, $22.5 \%$ of the species were used to cure two diseases, while the remaining $6.1 \%$ were used in the treatment of three or more diseases (such as Dracaena mannii Baker, Leonotis nepetifolia (L.) R.Br., Solanum incanum L.). Among the most cured diseases were gastrointestinal pathologies (diarrhea, vomit, stomach ache) cured by 11 species, weakness and faints (7 species), gynaecological, andrological and urinogenital disorders (erection,
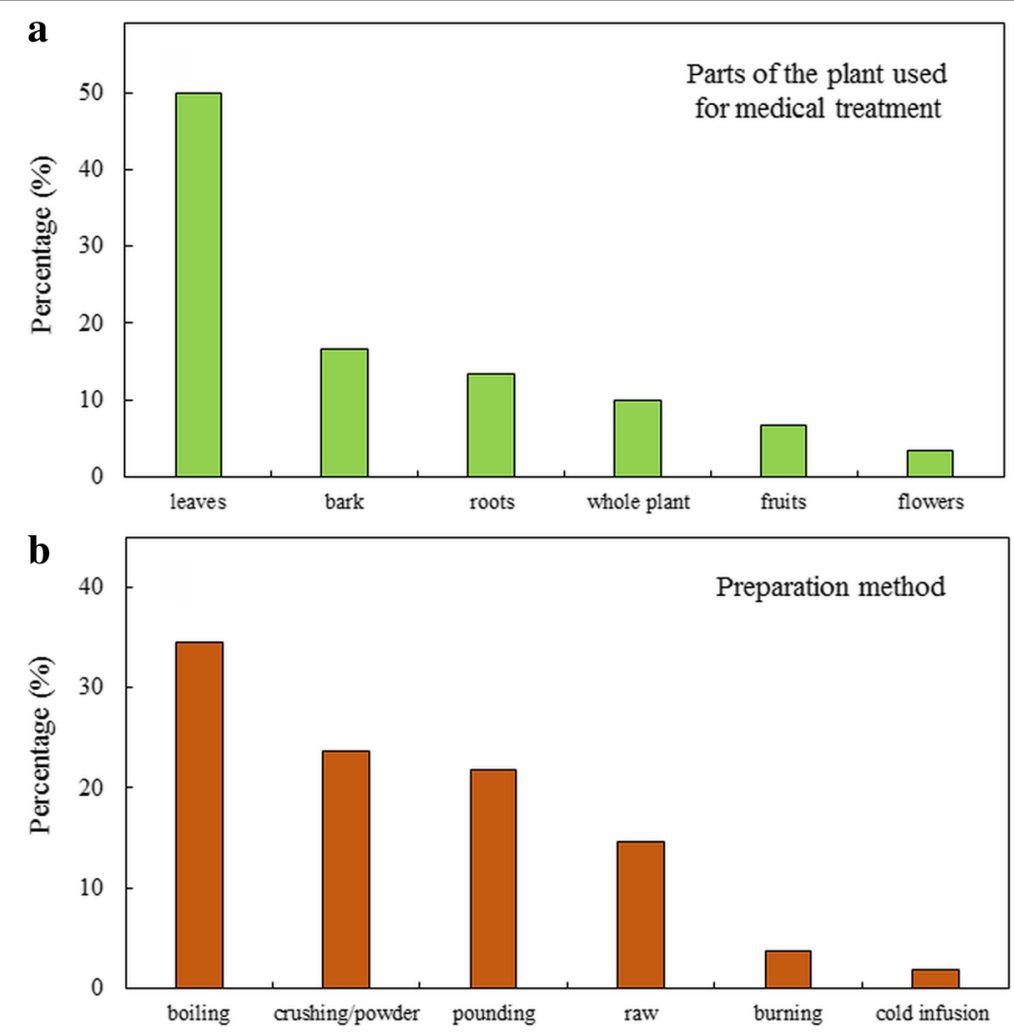

Fig. 5 Plant species for medical treatments. a Used parts of the plants; b preparation methods 


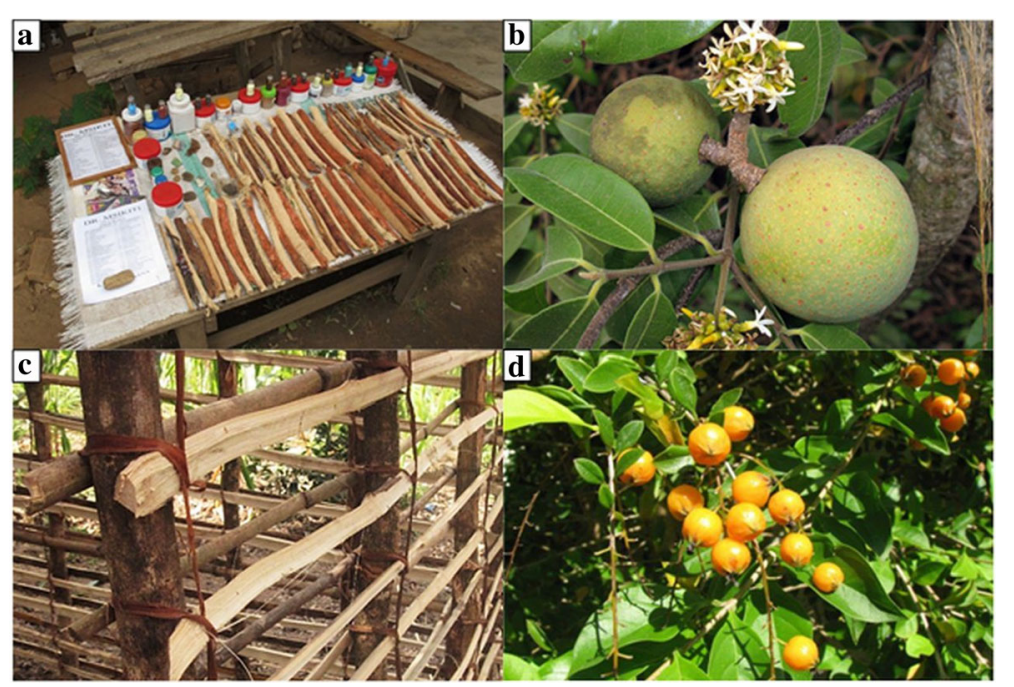

Fig. 6 Plant different uses. a Stand of a local healer with numerous barks for sale; $\mathbf{b}$ fruits of Landolphia kirkii Dyer, a wild liana; c the bark of Brachystegia sp. used to tie together the elements of traditional houses; d Duranta erecta L., a ritual species, used against misfortune

infertility, bleeding losses) cured by 7 species, respiratory diseases (cough, cold) (6 species), parasites (6 species), cardio-circulatory problems (4 species) and wounds (3 species) (Table 2). Other studies showed intestinal pathologies [5] and also wounds, respiratoty,

Table 2 Type of diseases cured by plants botanically identified in the area of study (see Table 1)

\begin{tabular}{ll}
\hline Disease & $\begin{array}{l}\text { Number of species } \\
\text { suitable for treatment }\end{array}$ \\
\hline Gastrointestinal & 11 \\
Weakness and faints & 7 \\
Gynaecological, andrological & 7 \\
and urinogenital & \\
Respiratory & 6 \\
Parasites & 6 \\
Cardio-circulatory & 4 \\
Wounds & 3 \\
Typhus & 2 \\
Pain and inflammations & 2 \\
Teeth and gums & 2 \\
Incontinence & 2 \\
Bites & 2 \\
Headaches & 2 \\
Eye problems & 2 \\
Diabetes & 1 \\
Hernia & 1 \\
Otitis & 1 \\
Anemia & 1 \\
\hline
\end{tabular}

urinogenital and cardio-circulatory (e.g. hypertension) disorders as those most frequently treated with medicinal plants [18].

Medicinal treatments were most commonly prepared by boiling the plant part containing the active substance $(34.5 \%)$, by crushing the dried part of the plant $(23.6 \%)$, or by pounding the fresh plant parts, $(21.8 \%)$, whereas sometimes the collected plant organs were used raw (18\%) (Fig. 5b). These results are in accordance with investigantions carried out in the same region [5] and in general with other ethnobotanical studies in Tanzania, in which boiling to make decotions and pounding/grinding resulted to be the most common medicine preparation methods $[13,18]$. Medical treatments were assumed by ingestion (77.4\%), by dermal application (20.8\%) and by inhalation (1.9\%). Considering also the unclassified species (Additional file 2), other ritual methods can be found, such as the dispersion on the ground of the drug.

It should be taken into account that many of the traditional healing methods are based on rituals, dreams and spirit evocations (typical of every local healer), which most of the times are believed to be more important than the actual effect of plant medicinal remedies. This further diversifies the picture of traditional medicine, which largely varies from tribe to tribe, according to their own tradition.

\section{Food and other plant uses}

In total 53 plants were also indicated for food use: 21 were species collected in the wild, 30 were cultivated and 2 were both cultivated or grow spontaneously in the 
wild. Most of these belong to the Fabaceae family (6 species), followed by Solanaceae, Asteraceae and Cucurbitaceae (3 species each). The parts of the plants mostly consumed as food were fruits and seeds (55.6\%), leaves (31.5\%), roots (7.4\%) and shoots (5.6\%). Wild food plants do not play a key role in the diet of these communities and are not commonly used as famine foods. According to the present data, wild fruits such as Landolphia kirkii Dyer or Vitex doniana Sweet fruits, are collected as snacks by people working in the fields; wild vegetables such as Bidens pilosa L., Lactuca inermis Forssk. or Asparagus flagellaris (Kunth) Baker are used as side dishes; other species like Piper capense L.f. are added as flavours to some main dishes.

In general, fruits were eaten raw, while vegetables were consumed cooked in $80 \%$ of cases, while the remaining $20 \%$ was consumed raw or used for infusion to extract the aromas, such as Cymbopogon citratus (DC.) Stapf. Among species commonly collected in the wild there were Bidens pilosa, an herb used as a vegetable, and the fruits of Landolphia kirkii Dyer (Fig. 6b). Instead, Telfairia pedata (Sm.) Hook., a native cultivated species for collecting seeds (in order to extract oil), was indicated as progressively disappearing due to its low productivity compared to the new species of oil plant recently introduced.

Twenty-eight (19.4\%) species were indicated as useful to produce raw materials (Fig. 4), of which 21 were woody species used for the production of furniture, house structural elements, firewood and poles. The other seven species were herbs (e.g., Poaceae and Cyperaceae) and palms which are mainly used for the production of fibers and roof covers (Fig. 6c). One of the most exploited species is Dalbergia melanoxylon Guill. \& Perr. used because of its dark wood to make carved objects, such as figurines and necklaces. Phoenix reclinata Jacq. and Musa $x$ paradisiaca L. were mainly used for the production of cordage and for weaving works as reported in Shangali et al. [19]

In addition, five other species (Fig. 4) were indicated as having ritual purposes linked to their traditional use within the communities. These species were thought to avoid bad luck (e.g., by drinking an infusion of Duranta erecta L. leaves and roots for 21 days, Fig. 6d), or against bad sprits or evil eye (e.g., bark of Ficus sycomorus L.). As also reported in [19], 2 plants were used to extract dyes (Bridelia micrantha (Hochst.) Baill. and Diospyros loureiroana G.Don). In the house gardens many species were just used as decoration, among which the most frequently cited by respondents were Dracaena fragrans, (L.) Ker Gawl. Bougainvillea spectabilis Willd. and Duranta erecta L. One wild tree (Brachystegia sp.) was indicated as pollen producer for bees, while the leaves of the wild poisonous tree Anthocleista grandiflora Gilg were used by local fishermens to stun fishes as also reported also by Shangali et al. [19]. Even in these rural community, as well as worldwide, Nicotiana tabacum L. leaves were used for the production of cigars. Finally, Capsicum chinense Jacq., Ocimum tenuiflorum L. and Bougainvillea spectabilis were indicated to be good repellent for insects (Fig. 4).

\section{Conclusions}

The present study revealed that numerous plant species are still essential in the everyday life of the tribes living in Kilombero Valley. These plants are commonly used for medicinal, food, weaving and building purposes. Most of the plants mentioned by the interviewed people were usually harvested in the wild, threatening the existence of some useful species. After the creation of the Udzungwa Mountains National Park, the collection areas were highly reduced concentrating the harvesting pressure on the few remaining areas of unprotected forest. Only few healers started to cultivate species for disease treatment, while almost all started to collect the plants in the neighbouring natural environment. Present data point out that half of the medicinal remedies were prepared from leaves (50\%), while $16.7 \%$ were obtained from bark, $13.3 \%$ from roots, and $10 \%$ from the whole herbaceous plant. Harvesting practices like root excavation and stem decortication are causing a progressive depletion of many medicinal plant species. In addition, deforestation makes medicinal species harvesting areas increasingly scarce, forcing many local healers to abandon the practice. In the light of these facts, it is essential, in the immediate future, to educate traditional healers as well as common people to the sustainable use of the surrounding natural heritage. It seems also necessary to provide the populations with additional means to increase the forested areas, such as the distribution of seedlings for biomass production. Although some efforts have already been made in the studied territory, and in spite of a firm tradition in Tanzania of community-based forest conservation, the situation remains critical and the state of unprotected forests near these villages is deteriorating year after year. This situation, if not quickly reversed, may lead to an unprecedented environmental crisis and to the loss of much of the traditional ethnobotanical culture. In this context, the present study wishes to contribute, at least to some exent, to preserving the knowledge present in the investigated populations, still deeply connected to nature, and to passing down this unevaluable tradition to future generations.

\section{Additional files}

Additional file 1: Questionnaire form used during the semi-striuctured interviews of the ethnobotanical survey. (PDF $271 \mathrm{~kb}$ )

Additional file 2: List of plants not classified mentioned in the study area. (PDF 97 kb) 


\section{Acknowledgements}

We wish to thank the Udzungwa Ecological Monitoring Centre (P.O. Box 99, Mang'ula - Tanzania) staff for their logistical help, Dr. Silvia Ricci and Dr. Francesco Rovero of the Mazingira Association (Trento, Italy) for the precious help provided in searching and contacting candidates for the interviews and Dr. Henry J. Ndangalasi (Dept. of Botany, Dar-es-Salaam Univerisity) for the collection of herbarium specimens. We also wish to thank Mr. Nicodemo Mele (University of Bologna) for helping in editing colour pictures and Dr. Marianne Louise van Buuren for edinting the English language.

\section{Funding}

Not applicable.

\section{Availability of data and materials}

All data generated or analysed during this study are included in this published article (and its Additional files).

\section{Authors' contributions}

MS and RV conducted field work and drafted the manuscript. RV and CB designed the study. AT contributed to the preparation and critical revision of the manuscript. All authors read and approved the final manuscript.

\section{Competing interests}

The authors declare that they have no competing interests.

\section{Consent for publication}

Not applicable.

\section{Ethics approval and consent to participate}

Not applicable.

\section{Author details}

'Department of Biological, Geological and Environmental Sciences, University of Bologna, via Irnerio 42, 40126 Bologna, Italy. ${ }^{2}$ MUSE - Museo delle Scienze, Corso del Lavoro e della Scienza, 3, 38122 Trento, Italy.

\section{Received: 5 December 2016 Accepted: 17 February 2017}

\section{Published online: 09 March 2017}

\section{References}

1. Cotton CM. Ethnobotany: principles and applications. Chichester: John Willey and Sons Ltd; 1996.

2. Abbiw DK. Useful plants of Ghana: West African uses of wild and cultivated plants. London: Intermediate Technology Publications and the Royal Botanic Gardens; 1990.

3. Kochhar SL. Economic botany in the tropics. 2nd ed. New Delhi: Macmillan India Ltd; 1998.

4. Cunningham AB. Applied ethnobotany: people, wild plant use and conservation. People and plants conservation manuals. London: Earthscan Publications Ltd. and VA USA: Sterling; 2001.

5. Amri E, Kisangau DP. Ethnomedicinal study of plants used in villages around Kimboza forest reserve in Morogoro, Tanzania. J Ethnobiol Ethnomed. 2012; 8:1. doi:10.1186/1746-4269-8-1.

6. Le Roux PJ. Supply of fuel-wood for rural populations in South Africa. South African Forestry J. 1981;117:22-7.

7. The World Bank. http://data.worldbank.org/indicator/SP.RUR.TOTL.ZS

8. World Health Organization. Traditional medicine. Fact sheet No 134; 2003 http://www.who.int/en/.

9. Kisangau DP, Lyaruu HV, Hosea KM, Joseph CC. Use of traditional medicines in the management of HIV/AIDS opportunistic infections in Tanzania: a case in the Bukoba rural district. J Ethnobiol Ethnomed. 2007;3:29. doi:10.1186/ 1746-4269-3-29.

10. Rural Poverty Portal. http://www.ruralpovertyportal.org/country/home/tags/ Tanzania.

11. Mahunnah RLA, Usio FC, Kayombo EJ. Documentary of traditional medicine in Tanzania. Dar-es-Salaam: Dar-es-Salaam University Press; 2012.

12. Gessler MC, Msuya DE, Nkunya MHH, Mwasumbi LB, Schär A, Heinrich M, Tanner M. Traditional healers in Tanzania: the treatment of malaria with plant remedies. J Ethnopharmacol. 1995;48(3):131-44.

13. Moshi MJ, Donald F, Otieno R, Mbabazi PK, Weisheit A. Ethnomedicine of the Kagera Region, Northwestern Tanzania. Part 2: the medicinal plants used in Katoro ward, Bukoba District. J Ethnobiol Ethnomed. 2010;6:9. doi: 10.1186/1746-4269-6-19.

14. Hall J, Burgess ND, Lovett J, Mbilinyi B, Gereau RE. Conservation implications of deforestation across an elevational gradient in the Eastern Arc Mountains, Tanzania. Biol Conserv. 2009;142:2510-21. doi:10.1016/j.biocon.2009.05.028.

15. Liengme CL. A study of wood use for fuel and building in an area of Gazankulu. Bothalia. 1983:14:245-57.

16. Moshi MJ, Otieno DF, Mbabazi PK, Weisheit A. The ethnomedicine of the Haya people of Bugabo ward, Kagera Region, Northwestern Tanzania. J Ethnobiol Ethnomed. 2009;5:24. doi:10.1186/1746-4269-5-24.

17. Schlage C, Mabula C, Mahunnah RLA, Heinrich M. Medicinal plants of the Washambaa (Tanzania): documentation and ethnopharmacological evaluation. Plant Biol. 2000:2:83-92. doi:10.1055/s-2000-296.

18. Moshi M, Otieno DF, Weisheit A. Ethnomedicine of the Kagera Region, Northwestern Tanzania. Part 3: plants used in traditional medicine in Kikuku village, Muleba District. J Ethnobiol Ethnomed. 2012;8:14. doi:10.1186/1746-4269-8-14.

19. Shangali CF, Mabula CK, Mmari C. Biodiversity and human activities in the Udzungwa Mountain Forest, Tanzania. Ethnobotanical survey in the Udzungwa Scarp Forest Reserve. J East Af Nat Hist. 1998;87:291-318. doi:10. 2982/0012-8317(1998)87[291:BAHAIT]2.0.CO:2.

20. Shangali CF, Zilihona IJE, Mwang'ingo PLP, Nummelin M. Use of medicina plants in the Eastern Arc Mountains with special reference to the Hehe ethnic group in the Udzungwa Mountains, Tanzania. J East Af Nat Hist. 2008:97(2):225-54. doi:10.2982/0012-8317-97.2.225.

21. Luoga EJ, Witkowski ET, Balkwill K. Differential utilization and ethnobotany of trees in Kitulaghalo forest reserve and surrounding communal lands, Eastern Tanzania. Econ Bot. 2000;54(3):328-43. doi:10.1007/BF02864785.

22. McGowan PJK, Dowell SD, Carroll JP, Aebischer NJ. Partridges, quails, francolins, snowcocks and guineafowl: status survey and conservation action plan 1995-1999. Switzerland: IUCN \& World Pheasant Association; 1995

23. Frost $P$. The ecology of miombo woodlands. In: Campbell B, editor. The Miombo in transition: woodlands and welfare in Africa. Bogor: Center for International Forestry Research; 1996. p. 1-57.

24. Signorini MA, Bruschi P, Camangi F, Guarrera PM, Pieroni A, Savo V. Metod della ricerca etnobotanica. In: Caneva G, Pieroni A, Guarrera PM, editors. Etnobotanica. Conservazione di una patrimonio culturale come risorsa per uno sviluppo sostenibile. Bari: Edipuglia; 2013. p. 44-67.

25. Alexiandes MN. Collecting ethnobotanical data: an introduction to basic concepts and techniques. In: Alexiandes MN, editor. Selected guidelines for ethnobotanical research: a field manual. New York: New York Botanical Garden; 1996. p. 53-94.

26. Sebastiani L, Camangi F, Stefani A. Plant biodiversity, recovery, and conservation: a case study from the val di Vara (La Spezia - Liguria). Acta Hortic. 2009:817:319-24.

27. Chalabra SC, Mahunnah RLA, Mshiu EN. Plants used in traditional medicine in Eastern Tanzania. VI. Angiosperms (Sapotaceae to Zingiberaceae). J Ethnopharmacol. 1993;39:83-103.

\section{Submit your next manuscript to BioMed Central and we will help you at every step:}

- We accept pre-submission inquiries

- Our selector tool helps you to find the most relevant journal

- We provide round the clock customer support

- Convenient online submission

- Thorough peer review

- Inclusion in PubMed and all major indexing services

- Maximum visibility for your research

Submit your manuscript at www.biomedcentral.com/submit
Biomed Central 